\title{
Gestión curricular en el desarrollo de las competencias transversales de los estudiantes en una universidad pública
}

\author{
Alan Alain Huaman Auccapuri \\ alan.huaman@unsaac.edu.pe \\ https://orcid.org/0000-0001-9386-9618 \\ Universidad Nacional de San Antonio Abad del Cusco \\ Zoraida Loaiza Ortiz \\ zoraida.loaiza@unsaac.edu.pe \\ https://orcid.org/0000-0002-8034-1993 \\ Universidad Nacional de San Antonio Abad del Cusco \\ Herminia Callo Sánchez \\ hcallo@uandina.edu.pe \\ https://orcid.org/0000-0002-0306-3803 \\ Universidad Andina del Cusco \\ Teresa Inca Roca Concha \\ tinca@undqt.edu.pe \\ https://orcid.org/0000-0002-7489-070X \\ Universidad Nacional Diego Quispe Tito del Cusco \\ Elizabeth Loayza Ortiz \\ elizabeth.loayza@unsaac.edu.pe \\ https://orcid.org/0000-0002-3850-2802 \\ Universidad Nacional de San Antonio Abad del Cusco \\ Luz Ana Carrión Salinas \\ 1carrion@uandina.edu.pe \\ https://orcid.org/0000-0001-9425-3188 \\ Universidad Andina del Cusco
}

\section{RESUMEN}

Las universidades del Siglo XXI deben incorporar e impulsar el desarrollo de las competencias transversales en su currículo, a través de una adecuada articulación en la gestión curricular, orientado a la utilización del conocimiento adquirido en el ejercicio profesional. El propósito del estudio fue evaluar la articulación de la gestión curricular universitaria con el desarrollo de competencias transversales en estudiantes universitarios. En tal circunstancia el método se fundamentó en el enfoque cuantitativo, de tipo explicativo, no experimental y transversal, la población estuvo conformado por 16951 estudiantes de pregrado, donde sus edades en su mayoría son de 19 a 27 años, 
distribuidos en 33 escuelas profesionales de la provincia del Cusco; la muestra representativa de la población fue de 243 obtenidos a través de un muestreo probabilístico estratificado. Los instrumentos correspondieron al cuestionario de percepción en escala de Likert, ambos instrumentos son confiables. Para la presentación de los resultados se utilizó los baremos con la finalidad de hacer más comprensible el análisis estadístico. Los resultados evidencian un nivel poco adecuado del 53,9\% del despliegue de la gestión curricular universitaria, por otra parte, el desarrollo de las competencias transversales alcanza un nivel mejorable del $60,9 \%$, demostrándose la existencia de problemas o dificultades que perjudican la debida articulación entre ambas variables, interpretación corroborada por el estadígrafo $\mathrm{H}$ de Kruskal-Wallis con un valor P inferior al margen de error del 5\%. En conclusión, la necesidad de lograr una mejor articulación entre la gestión curricular universitaria y las competencias transversales es necesario propiciar una adecuada composición, cohesión, coherencia y proyección de la gestión curricular, considerando en su estructura el desarrollo de las competencias instrumentales, personal y sistémicas del estudiante universitario.

Palabras clave: gestión curricular; currículo universitario; competencias genéricas; plan de estudios universitarios. 


\title{
Curriculum management in the development of transversal competences of students in a public university
}

\begin{abstract}
The universities of the XXI century must incorporate and promote the development of transversal competences in their curriculum, through an adequate articulation in the curricular management, oriented to the use of the knowledge acquired in professional practice. The purpose of the study was to evaluate the articulation of university curricular management with the development of transversal competences in university students. In this circumstance, the method was based on the quantitative approach, explanatory, nonexperimental and transversal, the population was made up of 16,951 undergraduate students, where their ages are mostly from 19 to 27 years, distributed in thirty-three professional schools from the province of Cusco; the representative sample of the population was 243 obtained through a stratified probability sampling. The instruments corresponded to the Likert scale perception questionnaire, both instruments are dependable. For the presentation of the results, the scales were used to make the statistical analysis more understandable. The results show an inadequate level of $53.9 \%$ of the deployment of university curricular management, on the other hand, the development of transversal competences reaches an improvement level of $60.9 \%$, demonstrating the existence of problems or difficulties that harm the due articulation between both variables, interpretation corroborated by the Kruskal-Wallis $\mathrm{H}$ statistic with a $\mathrm{P}$ value lower than the $5 \%$ margin of error. In conclusion, the need to achieve a better articulation between the university curricular management and the transversal competences is necessary to promote an adequate composition, cohesion, coherence, and projection of the curricular management, considering in its structure the development of the instrumental, personal, and systemic competences. of the university student.
\end{abstract}

Keywords: Curriculum management, university curriculum, generic competences.

Artículo recibido: 05 octubre. 2021 Aceptado para publicación: 02 noviembre 2021 Correspondencia: alan.huaman@unsaac.edu.pe Conflictos de Interés: Ninguna que declarar 


\section{INTRODUCCIÓN}

Las universidades aproximadamente hace 20 años han comenzado a incorporar a las competencias en sus planes curriculares, dejando de lado la producción de conocimientos, el cual se fundamenta por la investigación, aspecto tradicional. Actualmente en las universidades de Latinoamérica aun le está costando cambiar a un enfoque por competencias.

La enseñanza universitaria fue considerada como un proceso de divulgación del conocimiento, formando al estudiante para un contexto predecible y no cambiante, enfocándose en el aprendizaje conceptual (acumulación de conocimientos), de esta forma el futuro profesional debía adquirir un experiencia real cuando se desempeñe en un determinado puesto de trabajo, esto genero un gran problema, pues se tenía un divorcio entre la "universidad y el mercado laboral", debido a que las organizaciones demandan profesionales con experiencia, la cual podía ser adquirida mediante el ejercicio profesional (Villardón, 2016).

En la sociedad del conocimiento, aspecto característico del Siglo XXI, es necesario que las personas se encuentren en la capacidad de utilizar el conocimiento adquirido, actualizarlo y seleccionar aquellos que sean propios para un contexto específico, comprender la necesidad de aprender constantemente y concebir el potencial de lo aprendido, con la finalidad de adaptar el conocimiento aprendido a diversas situaciones reales (Yániz \& Villardón, 2006).

Las universidades procuran enfocarse en la tarea de formar estudiantes, para contribuir en el desarrollo sostenible de la sociedad, a través del ejercicio profesional competente, permitiéndoles afrontar las demandas del ámbito laboral. Es en este contexto donde la universidad debe responder a las demandas del mercado laboral, teniendo en cuenta su entorno cultural e histórico, en ese entender debe atender a las necesidades sociales mediante una adecuada articulación del perfil del egreso universitario, promoviendo el cambio social, propiciando la formación de profesionales capaces de promover y anticipar los cambios de la sociedad del conocimiento.

La pandemia del COVID - 19, ha desnudado la capacidad de repuesta o resiliencia a un contexto distinto de llevar a cabo la formación de profesionales universitarios, caracterizada principalmente por la educación virtual o remota, con situaciones y necesidades diferentes, debiendo tomar en cuenta las competencias que los estudiantes 
deben alcanzar en las diferentes profesiones, con el fin de responder a los intereses y necesidades de este nuevo milenio, fundamentándose en el logro de las competencias profesionales, proceso que viene definido en diseño curricular o plan de estudios.

La gestión curricular es un proceso arraigado por distintos procesos, conformado por etapas interrelacionadas de planeación, organización, ejecución y control. En estos diferentes procesos se requiere gestionar el currículo, teniendo en cuenta el proceso de planificar, organizar, ejecutar y verificar el cumplimiento de los objetivos establecidos, teniendo en cuenta los fundamentos didácticos. En estas etapas el currículo debe enfocarse en asegurar un mejoramiento continuo de la calidad en la educación superior universitaria, para tal hecho es necesario implementar y diseñar un seguimiento continuo, considerando obligatoriamente el desarrollo de las competencias (Concepción \& Rodríguez, 2016).

El estudiante universitario pasa por un proceso formativo desde el momento de su ingreso hasta su egreso, al termino deberá poner en práctica todo lo aprendido, capaces de asimilar los cambios vertiginosos de la tecnología de forma innovadora y creativa, para lograrlo requiere de transformaciones con las exigencias formativas en el proceso de enseñanza y aprendizaje, con el fin de responder a la demanda de la sociedad, lo cual debe estar debidamente definido en el proceso de la gestión curricular universitaria, debidamente articulado con las competencias que se desarrollaran para que el futuro egresado logre un óptimo desempeño profesional y social.

En presente estudio, teniendo en cuenta lo mencionado, desde la experticia de los investigadores, con relación a la gestión curricular en la Universidad Nacional de San Antonio Abad, durante los últimos 5 años la universidad se encontraba en proceso de licenciamiento institucional, requisito para continuar operando y otorgando grados académicos y títulos profesionales. Durante este proceso se evidenció en referencia al aspecto de la gestión curricular que no se encontraba orientado a la innovación, transformación y exigencias de formación que demanda la sociedad, evidenciando planes de estudio con más de 20 años de antigüedad, objetivos y perfiles poco ajustados a contexto actual, mismos que exige la sociedad del conocimiento.

Las principales falencias que se han evidenciado en la gestión curricular, es el componente curricular, donde se observa, asignaturas con sumillas que responden a un contexto educativo del Siglo XX, basado en la difusión y adquisición del conocimiento, 
lo cual no responde a las exigencias de la demanda laboral, actual. Otros aspectos problemáticos están enfocados en la articulación que debe proponer con el fin de alcanzar las ansiadas competencias profesionales de los futuros egresados, lo cual evidencia deficiencias en la coherencia y cohesión curricular, y también debería responder a políticas de mejora continua. Estas falencias son reflejadas durante el proceso formativo de los estudiantes universitarios, que abarca desde el proceso de matrícula, desarrollo del semestre académico, evaluaciones, y finalización, transcurriendo hasta la culminación del proceso formativo, y esto no acaba ahí porque luego se enfrentan a un proceso administrativo para obtener el título profesional, donde los procedimientos de homologaciones reflejan que no se ha tenido el debido cuidado en la elaboración de los cuadros de equivalencias entre planes de estudios y el mismo plan de estudios vigente; donde la gestión curricular, debe orientar y encaminar al logro de las competencias de los estudiantes, principalmente en las competencias transversales o genéricas, porque estas están directamente orientas en dotar de las habilidades, capacidades y destrezas necesarias para un óptimo desempeño profesional.

De acuerdo con los argumentos mencionados, el estudio recae en el propósito de evidenciar la necesidad de una gestión curricular, que responda a las necesidades y exigencias del proceso formativo de los estudiantes, previamente debe haber considerado las competencias que se pretende lograr, asimismo respondan a las demandas laborales del contexto actual. Para tal hecho la investigación ha seleccionado a los estudiantes de la Universidad Nacional de San Antonio Abad del Cusco, como parte de la población de estudio, universidad ubicada en Latinoamérica, específicamente en la República del Perú, departamento y provincia del Cusco; de esta manera se planteó el siguiente problema:

- ¿Está debidamente articulado la gestión curricular universitaria con el desarrollo de competencias transversales en estudiantes de pregrado?

Con la finalidad de responder a esta interrogante, se ha recurrido a estudios previamente realizados, tales como "Rediseño curricular de la carrera gestión social y desarrollo de la Universidad de Otavalo para su proceso de acreditación”, escrito por Hernández (2017), enfocándose en la realización de talleres multidisciplinarios, con la finalidad de permitir realizar un análisis integral de los componentes del rediseño curricular.

El estudio "Gestión curricular holística en el modelo por competencias: un estudio exploratorio", estudio escrito por Crespo et al. (2021), donde el propósito del estudio fue 
identificar el grado de aplicación de la gestión curricular holística en el proceso de diseño curricular en los distintos programas de pregrado en 52 universidades de 9 países de Latinoamérica.

En ese entender, en respuesta al problema formulado en el estudio, se tuvo por objetivo:

- Evaluar la articulación de la gestión curricular universitaria con el desarrollo de competencias transversales en estudiantes de pregrado

Igualmente, se ha considerado la revisión de fundamentos teóricos de la gestión curricular en el ámbito de la educación superior universitaria y las competencias transversales o genéricas, como se muestran en los siguientes párrafos.

\subsection{Gestión curricular universitaria}

La gestión curricular en el ámbito universitario es una herramienta fundamental para la toma de decisiones en el proceso formativo de los futuros profesionales, el cual debe responder a las expectativas del mercado laboral, a través de la actualización curricular.

\subsubsection{Currículo}

En la educación básica de los países Latinoamericanos como es el caso del Perú, responde a diferentes procesos educativos, donde se desenvuelven intereses, necesidades, condiciones, evaluaciones y análisis posteriores, con la finalidad de atender a las razones y los objetivos de la escolarización, permitiendo responder a la problemática curricular, tiendo en cuenta los procesos de aprendizaje de los estudiantes para profundizar en un área curricular determinada (Benavidez \& Vásquez, 2019, p. 17).

El currículo de acuerdo con Osorio (2017) hace referencia a un constructo histórico, que engloba su teoría como su praxis, esta además es establecida por cada sociedad educativa en base a su entendimiento respecto a la relación teoría-Practica, Escuela-Sociedad, además del papel de cada uno de los integrantes inmersos en las entidades educativas. Por tanto, desde la perspectiva de la praxis educativa el currículo es un planteamiento que detalla explícitamente conjunto de métodos y contenidos, dispone además una apertura para recomendaciones con relación a aspectos que pueden inferirse relevantes y factibles en el proceso de enseñanza-aprendizaje en el salón de clases. Con todo lo mencionado el currículo se compone en un planteamiento hipotético de la labor educativa (pp. 150-151).

\subsubsection{Educación y gestión curricular}

La gestión curricular es definida por Osorio (2017) como un conglomerado de procedimientos mismos que se hallan direccionados a un propósito de formación, de 
viabilizar un determinado aprendizaje. La educación es un proceso que implica enseñar y preparar a una persona, de manera que pueda desenvolverse sensatamente en contextos nuevos, apoyándose en la experiencia, la aprehensión de información, cultura y su adaptación e inclusión en la sociedad; siendo estos aspectos los que la hacen a la educación más compleja frente a la instrucción ya que esta se limita a transferir criterios prescriptivos y normativos, teorías o destrezas técnicas. El proceso educativo enmarca niveles los cuales buscan englobar las distintas dimensiones del Acto Educativo.

- La dimensión teórica: Plantea a la educación en base a los conocimientos brindados en la enseñanza.

- La dimensión de la praxis: Por su naturaleza practica sugiere a la educación, buscar generar ciertos cambios y efectos respecto a la realidad.

- La dimensión normativa: Plantea a la educación que propicie y favorezca la reflexión respecto de lo que la persona deba ser.

La educación arraiga dos conceptos paralelos y complementarios, mismos que deben distinguirse: la enseñanza y el aprendizaje. En tanto la enseñanza busca mostrar algo a los demás, el aprendizaje vendría a ser su proceso complementario, su efecto (p. 259).

La gestión curricular comprende el accionar educativo que se enfoca en la elaboración de escenarios adecuados para la comprensión y la argumentación, posibilitando la comunicación y generación de saberes (Osorio, 2017). De acuerdo con Swain \& Grasa (2010) el Instituto Tecnológico de Monterrey, lo define como una técnica educativa sustentada en el proceso lógico y con un sustento psicológico direccionado a guiar el aprendizaje del educando.

\subsubsection{Currículo universitario peruano}

Villalaz y Medina (2020) consideran que, en las universidades del Perú, la problemática del currículo engloba diversos aspectos, mismos que por su complejidad, necesitan ser examinados con base al contexto y la actualidad de la educación, y de esta manera perseguir la calidad universitaria. Por tanto, al tratar los componentes del currículo, se vuelve en una oportunidad para motivar respuestas, además de alternativas factibles para una transformación educativa, lo que conllevaría a una mejora de la sociedad.

En la pretensión de promover el ejercicio reflexivo, se consideran aspectos culturales, económicos y sociales de los educandos como parte de la realidad situacional actual; como lo fue la reciente repercusión de la Ley N³0220, “Ley Universitaria”, en el ámbito 
de regulación y funcionamiento de las entidades de educación superior universitaria en el Perú.

En esa misma línea se considera el modelo de licenciamiento dispuesta por la Superintendencia Nacional de Educación Superior Universitaria (SUNEDU), la cual compone una exigencia de orden primera en el reconocimiento de la calidad educativa. Además, será parte del análisis el examinar la manera de articulación del currículo con respecto a las áreas y ámbitos estratégicos que necesiten de atención y la indagación de tendencias en relación con "modelos de acreditación” que influyan en su definición y composición (p. 122).

\subsubsection{Modelos de gestión curricular}

La relevancia de la educación surge de un peculiar valor al examinar sus distintas estructuras y niveles, como las particularidades y medios con los que cuentan las instituciones que la imparten.

Morantes y Acuña (2013) desarrollaron una investigación en la cual denotan que las materias de estudio han ido modificándose, pasando de los estudios enfocados en tecnologías hacia los centrados en el cambio y la gerencia, por tanto, son de relevancia todos los puntos vinculados con la gerencia de la educación (liderazgo, estrategia, la calidad educativa, etc.); por su parte Pardasani (2018) manifiesta que es factible operar con innovadores modelos curriculares, los cuales no solo se limitan a lo académico sino que abarcan en alguna medida a todos las partes integrantes de la gestión curricular.

Un modelo de gestión de acuerdo con Duque (2009) hace referencia a la manera de organizar, manejar y combinar los recursos para alcanzar con los propósitos planteados. Engloba además a las procedimientos, pautas y políticas para optimizar el desempeño de una organización. En base a lo mencionado, la gestión curricular se orienta por procesos fijados por la institución en sí, congeniada por la organización, el uso de los recursos con los que se cuenta y primordialmente persiguiendo la continua optimización de los programas académicos. Por tanto, es factible reconocer que existen diversos modelos de gestión que muestran estructuras distintas, como también propician procesos diferentes que posibilitan a la entidad de educación superior a ahondar en la gestión del currículo. Producto de lo mencionado se muestra el modelo elaborado por Álamo (2015). 


\section{Figura 1}

Diseño curricular de los programas nacionales de formación

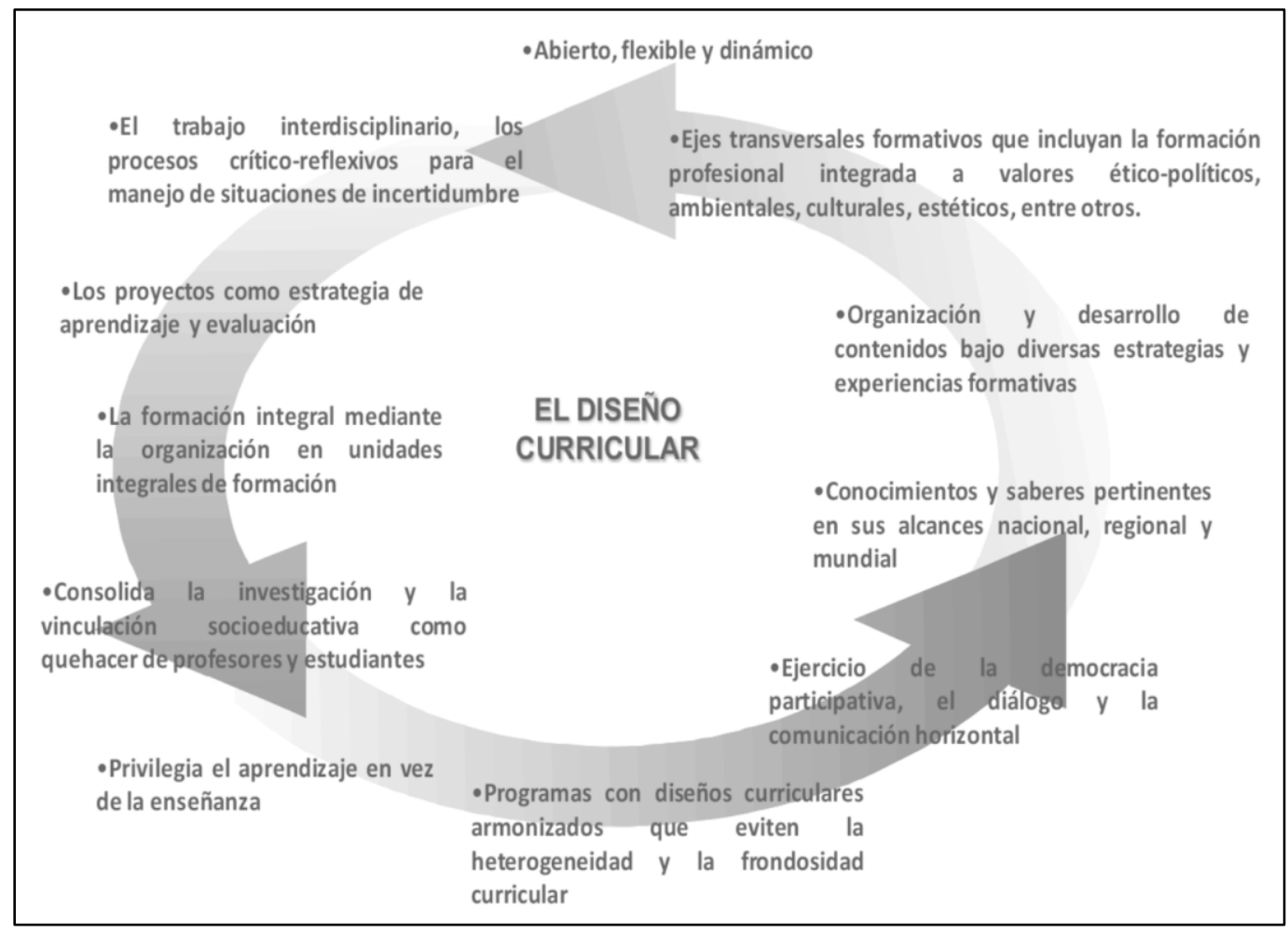

Nota: Seleccionado por Álamo (2015) del documento de la Universidad Politécnica.

\subsection{Competencias transversales o genéricas en universitarios}

En la actualidad el potencial de las competencias transversales no es objetadas, aun cuando su desarrollo en el ámbito educativo muestra cierta endeblez, razón por la cual se incentiva a impeler respuestas adecuadas que conduzcan a las entidades rumbo al afianzamiento de sus nuevos enfoques pedagógicos y funciones. Pérez et al. (2013) afirma que los "planes de estudio" se elaboraron con ciertas deficiencias referidas a la integración de las competencias transversales en los currículos universitarios, lo cual es imputado a la evolución continua por las que atraviesan las competencias, y a la complejidad ocasionada por el proceso de delimitación, de cuales implantar y transmitir durante el desarrollo de la carrera universitaria y en relación a su importancia profesional, sumando a lo ya mencionado otros inconvenientes didácticos vinculadas a las estrategias metodológicas para su enseñanza o evaluación. Por su parte Sánchez et al. (2010) hacen notar en las universidades la importancia de ejecutar estudios que muestren la realidad de estas entidades, para de esta forma realizar un monitoreo y brindar el respaldo que se requiere para la implantación definitiva de estas competencias en las casas de estudio superior universitaria. 


\subsubsection{Competencias en la educación básica}

Las competencias de acuerdo con el Ministerio de Educación del Perú (2017) hacen referencia a la virtud que posee un individuo para emplear un grupo de capacidades con la intención de alcanzar un objetivo concreto, en un determinado contexto, procediendo de forma adecuada y con un sentido ético. Ser competente involucra entender las circunstancias que se afrontara y analizar las alternativas con las que se cuenta para solucionarla. Por tanto, esto nos encamina a distinguir las capacidades y conocimientos que se poseen o que estas se hallen aptas a ser empleadas en el entorno, evaluar las combinaciones más apropiadas a las circunstancias y al objetivo, para posteriormente tomar una decisión; y llevar a cabo o ejecutar la combinación que se escoja.

Ser competente además involucra concertar ciertas particularidades personales, con virtudes socioemocionales que propicien con los demás una efectiva interacción. Esto mantendrá alerta en una persona con relación a sus estados emocionales, disposiciones subjetivas o valoraciones personales y la de los demás, debido a que estas dimensiones incidirán en la evaluación y elección de alternativas, como en su desenvolvimiento al momento de obrar o proceder. Actualmente la educación no se encuentra articulada con la educación universitaria, de tal forma que el desarrollo de las competencias transversales, no se articulan con las necesidades de la formación profesional de los estudiantes universitarios.

\subsubsection{Competencias en la sociedad del conocimiento}

Eurostat [Statistics Explained] (2016) afirma que la "sociedad del conocimiento" cierra el ciclo de globalización con una crisis social y económica, lo que ha ocasionado un aumento en la formación en todos los niveles. Por tanto, se acrecentó la cantidad de titulados en un contexto laboral cada vez más complicado e incierto, y que se halla amenazada por la "cuarta revolución industrial”. En nuestros días esta realidad es particularmente relevante y notoria en los universitarios, quienes persiguen su integración al mercado laboral. Sin embargo, las altas tasas de desempleo en este segmento truncan el desarrollo profesional de los egresados universitarios.

Por su parte Prising (2017) menciona que al adjuntar el conocimiento a la estructura de las economías sofisticadas ocasiona el surgimiento de modelos de producción diferentes, y con esto una novedosa noción de profesionalismo fundado en los nuevos requerimientos de competencias y cualidades. Las ocupaciones vinculadas al empleado del conocimiento 
son variables y flexibles en términos de localización y labores a ejecutar, sus requerimientos prestacionales actualmente se hallan en proceso de descubrimiento, es en este punto donde toma significado el desarrollo de competencias altamente personales y sociales que motiven un constante aprendizaje, el empleo innovador de los conocimientos, así como también la valoración del talento requerido para diferenciarse, adaptarse y extender sus opciones laborales.

La controversia entre la ocupación y la adaptación formativa se mantiene y actualmente es de importancia para las políticas educativas y económicas de las naciones, con lo cual se genera conexión entre el mercado laboral y los jóvenes que pretenden insertarse en ella.

\subsubsection{Competencias transversales o genéricas}

En el contexto de la educación superior, acorde a la Unión Europea (2015) la competencia es definida como "la capacidad comprobada de emplear conocimientos, virtudes y habilidades personales, metodológicas y sociales, en contextos de estudio, de desempeño laboral, además del desarrollo personal y profesional” (p. 22). Es por ello por lo que al momento de la evaluación de rendimiento estudiantil no solamente importa el conocimiento, sino como este puede ser aplicado y empleado, y que se puede conseguir con el mismo, utilizando valores y estándares metodológicos; son estos aspectos los que lo diferencian de la educación tradicional.

La definición de las competencias transversales para Alsina et al. (2011) hace referencia a una competencia instrumental global que engloba demás competencias de tipo lingüístico, tecnológico y cognitivo: la cualidad para la síntesis y análisis, la destreza en la comunicación oral y escrita, o capacidades informáticas esenciales. Las competencias se llevan a cabo en tres niveles: transferencia de información, la indagación y gestión, y la identificación de requerimientos de información (p. 27-28).

\subsubsection{Empleabilidad y las competencias genéricas o transversales}

En la escena educativa las universidades deben enfocarse en el desarrollo de las competencias transversales ("soft skills" o competencias blandas) adjudicarse funciones que vayan más allá de las tradicionales vinculadas a la educación netamente cognitiva y diciplinar (Andrews \& Higson, 2008). Actualmente este asunto es alarmante, siendo tratado en el ámbito formativo y laboral, la Unión Europea, por medio de los informes Education and Training 2010 y Education and Training 2020, divulga la guía y normativa 
de Horizonte 2020, además estos informes conceden a las universidades la obligación y compromiso de brindar a sus egresados de todas las competencias necesarias para lograr alcanzar puestos laborales y que puedan desenvolverse de la mejor manera en los mismos; es decir deben tratar de sobrepasar la brecha entre el marco sociolaboral y formativo, y de esta manera lograr un cambio en la empleabilidad por medio del aprendizaje constante e intensional.

la empleabilidad es una noción compleja y extensa que no solamente se centra en el fomento y motivación de los egresados para su inserción al campo laboral, sino además se vincula a la oportunidad de crecimiento profesional dentro y fuera de una organización (Rodríguez et al., 2010). En el contexto actual donde la innovación y la globalización abarcan cada vez más todos los ámbitos, donde la educación no es ajena a esta realidad por tanto cada vez se pretende dejar de lado un enfoque tradicionalista y pasar a uno en donde se transmita todas las competencias genéricas, transversales a los estudiantes, con lo cual se les proporcione todas la herramientas para que se puedan insertar al ámbito laboral sin ningún problema.

Las competencias genéricas no se hallan enmarcadas a un ámbito en particular o vinculadas de forma instrumental a las áreas disciplinares. Debido a su naturaleza estas competencias engloban a todas las áreas curriculares y a todos los niveles, su aprendizaje depende en gran porcentaje del desempeño de los docentes, no solo por el contenido que imparten, sino por la manera en cómo se realiza este proceso (Rey, 2001). Sin embargo, esta labor no es el rol especifico de alguno de los actores inmersos en la comunidad universitaria, motivo por el cual el fomento y transmisión de las competencias pueden quedar en un vacío, donde no se la traslade a la práctica, ni influya en el aprendizaje del estudiantado. Por tanto, es importante que la entidad educativa asuma la responsabilidad para articularlas, planificándola y brindando el soporte a los docentes y estudiantes para la praxis y desarrollo de dichas competencias.

\section{MATERIALES Y MÉTODOS}

La población objetivo de investigación, sobre el cual se pretendió generalizar los resultados de un total de 16951 estudiantes con registro de matrícula en el semestre académico 2021-I de la Universidad Nacional de San Antonio Abad, ubicado en el distrito, provincia y departamento del Cusco, donde las edades fluctúan en su mayoría entre 19 a 27 años. Se han seleccionado solamente las 33 escuelas profesionales que se 
encuentran en la provincia del Cusco, de tal forma, no fueron tomados en cuenta las escuelas profesionales de las filiales.

La técnica muestral consistió en la selección de los estudiantes participantes considerando las áreas agrupadas por escuelas profesionales, elaborado por la Dirección General de Admisión de la Universidad Nacional de San Antonio Abad, determinando los estratos con las ramas coincidentes del conocimiento. Posteriormente se realizó el procedimiento muestral estratificado, en este caso fueron las áreas agrupas del conjunto de estudiantes. Para calcular la muestra representativa de la población, previamente se realizó una prueba piloto, obteniéndose en el caso de la probabilidad de ocurrencia del evento " $p=0,8$ " y la probabilidad desfavorable de ocurrencia del evento " $q=0,2$ "; con un margen de error del 0,05 y una desviación normal estándar $\mathrm{Z}=1,96$. Realizado el cálculo de la muestra para población finita, se obtuvo $n=242,36 \approx 243$, de esta forma el número de estudiantes seleccionados fueron 243, distribuidos por estratos, conforme se muestra en la tabla 1.

\section{Tabla 1}

Distribución de los estudiantes por área de conocimiento, escuelas profesionales y estratos de la muestra

\begin{tabular}{|c|c|c|c|c|c|}
\hline Área & $\begin{array}{l}\text { Escuelas } \\
\text { profesionales }\end{array}$ & $\begin{array}{c}\text { \# de } \\
\text { estudiantes }\end{array}$ & $\begin{array}{l}\text { Participan } \\
\text { tes por } \\
\text { Área }\end{array}$ & $\begin{array}{l}\text { Porcent } \\
\text { aje por } \\
\text { Área }\end{array}$ & $\begin{array}{c}\text { \# participantes por } \\
\% \text { de muestra } \\
\text { estratificada }\end{array}$ \\
\hline $\begin{array}{l}\text { Ingeniería } \\
\text { y Ciencias } \\
\text { Básicas } \\
\text { (A) }\end{array}$ & $\begin{array}{l}\text { Arquitectura } \\
\text { Ingeniería Eléctrica } \\
\text { Ingeniería Geológica } \\
\text { Ingeniería Metalúrgica } \\
\text { Ingeniería de Minas } \\
\text { Ingeniería Mecánica } \\
\text { Ingeniería Química } \\
\text { Ingeniería Civil } \\
\text { Química } \\
\text { Física } \\
\text { Matemática } \\
\text { Ingeniería Informática } \\
\text { y de Sistemas } \\
\text { Ingeniería Electrónica } \\
\text { Ingeniería } \\
\text { Petroquímica }\end{array}$ & $\begin{array}{l}423 \\
586 \\
487 \\
506 \\
592 \\
481 \\
509 \\
680 \\
155 \\
148 \\
193 \\
568 \\
465 \\
165\end{array}$ & 5958 & $35 \%$ & 85 \\
\hline $\begin{array}{l}\text { Ciencias de } \\
\text { la Salud } \\
\text { (B) }\end{array}$ & $\begin{array}{l}\text { Agronomía } \\
\text { Biología } \\
\text { Enfermería } \\
\text { Farmacia y Bioquímica } \\
\text { Medicina Humana } \\
\text { Zootecnia } \\
\text { Odontología }\end{array}$ & $\begin{array}{l}604 \\
675 \\
318 \\
465 \\
542 \\
272 \\
243 \\
\end{array}$ & 3119 & $18 \%$ & 45 \\
\hline
\end{tabular}




\begin{tabular}{|c|c|c|c|c|c|}
\hline $\begin{array}{l}\text { Ciencias } \\
\text { Empresaria } \\
\text { les } \\
\text { (C) }\end{array}$ & $\begin{array}{l}\text { Ciencias } \\
\text { Administrativas } \\
\text { Contabilidad } \\
\text { Economía } \\
\text { Turismo } \\
\end{array}$ & $\begin{array}{c}930 \\
1048 \\
769 \\
678 \\
\end{array}$ & 3425 & $20 \%$ & 49 \\
\hline $\begin{array}{c}\text { Ciencias } \\
\text { Sociales } \\
\text { (D) }\end{array}$ & $\begin{array}{l}\text { Antropología } \\
\text { Arqueología } \\
\text { Derecho } \\
\text { Historia } \\
\text { Ciencias de la } \\
\text { Comunicación } \\
\text { Psicología } \\
\text { Filosofía } \\
\text { Educación } \\
\end{array}$ & $\begin{array}{c}346 \\
310 \\
665 \\
415 \\
667 \\
478 \\
109 \\
1459 \\
\end{array}$ & 4449 & $26 \%$ & 64 \\
\hline Total & 33 & $N=16951$ & & $100 \%$ & $n=243$ \\
\hline
\end{tabular}

Nota: Datos seleccionados del Compendio Estadístico Nro. 35, elaborado por la

Unidad de Estadística de la Universidad Nacional de San Antonio Abad.

El método de la investigación consideró un enfoque cuantitativo, de tipo explicativo, orientado al estudio de la causalidad de la variable dependiente, en este caso son las competencias transversales en estudiantes universitarios, a través del factor denominado gestión curricular universitaria, la cual se viene impulsando en el estado de emergencia sanitaria, provocado por la pandemia del COVID - 19. Hernández y Mendoza (2018), menciona la clasificación de dos diseños, pero en el caso del estudio se utilizó el diseño no experimental, específicamente el "transversal causal”, para tal hecho se realizó la medición de ambas variables, de acuerdo con la operacionalización de las variables como se muestra en la tabla 2.

\section{Tabla 2}

Operacionalización de las variables gestión curricular universitaria y competencias transversales

\begin{tabular}{|c|c|c|}
\hline Variables & Dimensiones & Indicadores \\
\hline \multirow{4}{*}{$\begin{array}{l}\text { Gestión } \\
\text { curricular } \\
\text { universitaria }\end{array}$} & Composición curricular & $\begin{array}{l}\checkmark \text { Organización del plan de estudios } \\
\checkmark \text { Semestralización de asignaturas y } \\
\text { prerrequisitos }\end{array}$ \\
\hline & Cohesión curricular & $\begin{array}{ll}\checkmark & \text { Cohesión de las asignaturas por áreas } \\
\text { curriculares }\end{array}$ \\
\hline & Coherencia curricular & $\begin{array}{ll}\checkmark & \text { Articulación con propósitos educativos } \\
\checkmark & \text { Articulación con el perfil profesional }\end{array}$ \\
\hline & Proyección del curricular & $\begin{array}{ll}\checkmark & \text { Políticas de mejora continua } \\
\checkmark & \text { Articulación con el mercado laboral }\end{array}$ \\
\hline
\end{tabular}




\begin{tabular}{|c|c|c|}
\hline \multirow{3}{*}{$\begin{array}{l}\text { Competencias } \\
\text { transversales }\end{array}$} & $\begin{array}{l}\text { Competencias } \\
\text { instrumentales }\end{array}$ & $\begin{array}{ll}\checkmark & \text { Organización y planificación } \\
\checkmark & \text { Comunicación verbal y escrita } \\
\checkmark & \text { Empleo de las tecnologías de la } \\
& \text { información y comunicación } \\
\checkmark & \text { Toma de decisiones } \\
\checkmark & \text { Diseño y gestión de proyectos } \\
& \text { profesionales y personales } \\
\checkmark & \text { Gestión de la información y } \\
& \text { comunicación } \\
\end{array}$ \\
\hline & Competencias personales & $\begin{array}{ll}\checkmark & \text { Interacción social } \\
\checkmark & \text { Trabajo en equipo } \\
\checkmark & \text { Control emocional } \\
\checkmark & \text { Compromiso profesional ético y social }\end{array}$ \\
\hline & Competencias sistémicas & $\begin{array}{ll}\checkmark & \text { Actitud emprendedora } \\
\checkmark & \text { Adaptabilidad } \\
\checkmark & \text { Creatividad e innovación } \\
\checkmark & \text { Motivación } \\
\checkmark & \text { Investigación } \\
\checkmark & \text { Trabajo autónomo } \\
\end{array}$ \\
\hline
\end{tabular}

Nota: Revisión y adaptación de Benavidez y Vásquez (2019) en referencia a la gestión curricular universitaria y González y Martínez (2020) en relación con las competencias

\section{transversales o genéricas.}

La técnica de recolección de la información utilizada fue la encuesta, con el fin de cuantificar las variables en estudio, de manera también que se usó el cuestionario como instrumento de recolección de la percepción que tienen los estudiantes respecto a la gestión curricular y el desarrollo de las competencias transversales. Los cuestionarios fueron confeccionados por los investigadores que forman parte del artículo científico, ambos instrumentos tuvieron como respuesta una escala de percepción de 5 niveles de tipo Likert, el cuestionario de gestión curricular universitaria conformado por 20 ítems y el cuestionario de competencias transversales conformado con 21 ítems. De la revisión del índice de consistencia interna Alfa de Cronbach, se obtuvo del cuestionario de gestión curricular universitaria $\alpha_{1}=0,811$ y en el caso del cuestionario de competencias transversales en estudiantes universitarios $\alpha_{2}=0,859$, como los valores son mayores al valor de 0,8 quedó demostrado la fiabilidad de los instrumentos de la investigación.

La presentación de los resultados fue dado a través de los siguientes baremos, cuya principal finalidad fue, porque, posibilitó mostrar los datos de una forma más comprensible, asimismo responde a la necesidad de mostrar el grado de desarrollo de las competencias transversales. 


\section{Tabla 3}

Baremos de la variable gestión curricular universitaria

\begin{tabular}{|l|l|l|}
\hline \multicolumn{1}{|c|}{ Rango } & Categoría o nivel & \multicolumn{1}{|c|}{ Descripción } \\
\hline $20-46$ & Inadecuado & $\begin{array}{l}\text { Los procedimientos establecidos en la gestión } \\
\text { curricular no responden adecuadamente a los } \\
\text { propósitos de formación profesional de los } \\
\text { estudiantes. }\end{array}$ \\
\hline $47-73$ & Poco adecuado & $\begin{array}{l}\text { Los procedimientos establecidos en la gestión } \\
\text { curricular en alguna medida se ajustan a los } \\
\text { propósitos de formación profesional de los } \\
\text { estudiantes. }\end{array}$ \\
\hline $74-100$ & Adecuado & $\begin{array}{l}\text { Los procedimientos establecidos en la gestión } \\
\text { curricular responden a los propósitos de formación } \\
\text { profesional de los estudiantes a través de un óptimo } \\
\text { aprendizaje. }\end{array}$ \\
\hline
\end{tabular}

Tabla 4

Baremos de la variable competencias transversales

\begin{tabular}{|l|l|l|}
\hline \multicolumn{1}{|c|}{ Rango } & Categoría o nivel & \multicolumn{1}{|c|}{ Descripción } \\
\hline $21-49$ & Insatisfactorio & $\begin{array}{l}\text { El estudiante no está desarrollando su capacidad } \\
\text { cognitiva, autónoma y reflexiva crítica en su } \\
\text { cotidianidad. }\end{array}$ \\
\hline $50-77$ & Mejorable & $\begin{array}{l}\text { El estudiante se encuentra en proceso de mejorar su } \\
\text { capacidad cognitiva, autónoma y reflexiva crítica. }\end{array}$ \\
\hline $78-105$ & $\begin{array}{l}\text { El estudiante ha desarrollado satisfactoriamente su } \\
\text { capacidad cognitiva, autónoma y reflexiva crítica, } \\
\text { producto del pensamiento crítico, dado por la } \\
\text { actitud reflexiva, activa y autónoma en su } \\
\text { cotidianidad. }\end{array}$ \\
\hline
\end{tabular}

El procesamiento fue realizado en el programa estadístico IBM SPSS en su versión 28, para obtener el análisis de los datos, presentados mediante barras de error para mostrar el comportamiento comparativo que se tiene en las diferentes áreas del conocimiento (grupo A, B, C y D), se aplicó el estadígrafo H Kruskal-Wallis o ANOVA de Kruskal-Wallis, con fin de alcanzar el objetivo del estudio, debido a la adopción de los baremos no fue necesario realizar el análisis de la distribución normal de los datos, tampoco es necesario para aplicar el estadígrafo de H Kruskal-Wallis. Adicionalmente se ha realizado el análisis comparativo por género (masculino y femenino) del estudiante con el estadígrafo U Mann-Withney. (Elorza, 2008) 


\section{RESULTADOS Y DISCUSIÓN}

\subsection{Resultados}

Los resultados están presentados comparativamente por el género del estudiante y posteriormente por el área de conocimiento: A. Ingeniería y Ciencias Básicas, B. Ciencias de la Salud, C. Ciencias Empresariales y D. Ciencias Sociales.

\section{Tabla 5}

Estadísticos descriptivos de la gestión curricular universitaria

\begin{tabular}{lll}
\hline Categorías & Frecuencia & Porcentaje \\
\hline Inadecuado & 4 & $1,6 \%$ \\
Poco adecuado & 131 & $53,9 \%$ \\
Adecuado & 108 & $44,4 \%$ \\
Total & 243 & $100,0 \%$ \\
\hline Los resultados evidencian una gestión curricular universitaria poco adecuado,
\end{tabular}
representado por el 53,9\%. Estos porcentajes demuestran un nivel poco adecuado de la gestión curricular en la universidad, donde la composición curricular, algunas asignaturas no es tan debidamente semestralizadas y organizadas en el plan de estudios, la cohesión y coherencia curricular carece de la articulación con los propósitos educativos y el perfil profesional del egresado, asimismo no se evidencian políticas realizables de mejora continua y la debida articulación con el mercado laboral. En el nivel adecuado se observa solamente un $44,4 \%$ de aciertos respecto a la composición curricular, la cohesión, coherencia y proyección curricular los cuales si responden a los propósitos educativos.

\section{Tabla 6}

Rangos promedio de la gestión curricular universitaria por el género de los estudiantes

\begin{tabular}{llccc}
\hline & Género & N & $\begin{array}{c}\text { Rango } \\
\text { promedio }\end{array}$ & $\begin{array}{c}\text { Suma de } \\
\text { rangos }\end{array}$ \\
\hline Gestión & Femenino & 130 & 119,00 & 15470,00 \\
universitaria & Masculino & 113 & 125,45 & 14176,00 \\
& Total & 243 & & \\
\hline
\end{tabular}

$\overline{\text { Los rangos promedio de los géneros masculino y femenino es similar lo cual denota que }}$ ambos casos no presentan diferencias en cuanto a la percepción de la gestión curricular universitaria. Entonces ambos casos géneros de estudiantes perciben que la gestión curricular que vienen desarrollando en las distintas escuelas profesionales presentan las mismas dificultades, tales como poca organización del plan de estudios de acuerdo con la semestralización de las asignaturas y prerrequisitos que ocasionan más tiempo de estudios 
o la no conclusión de los estudios de pregrado en el tiempo previsto. En el caso de la cohesión y coherencia curricular se observa que no está respondiendo a los propósitos educativos de cada escuela profesional de la universidad.

\section{Figura 2}

Barras de error de la gestión curricular por género

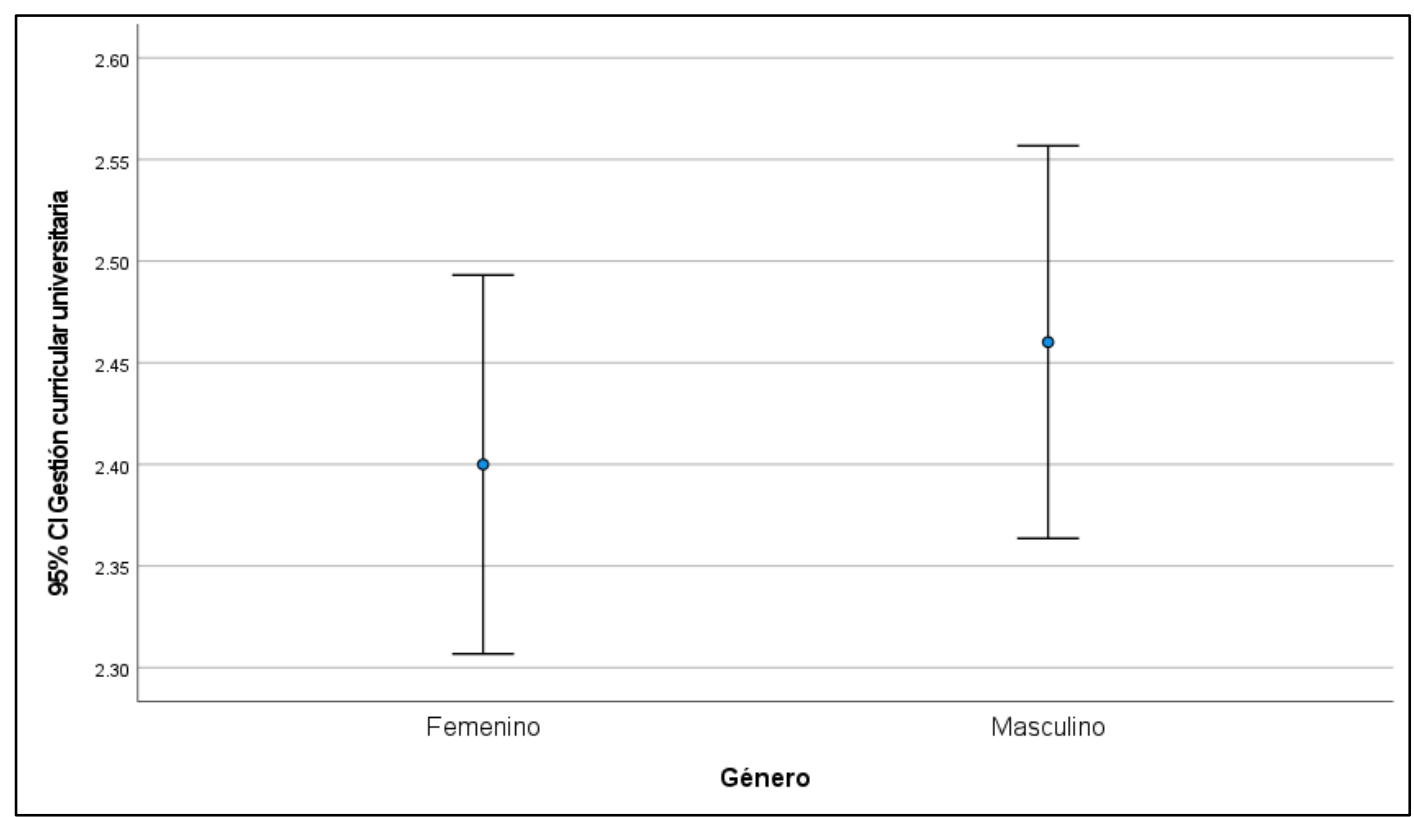

Nota: Resultados del programa estadístico IBM SPSS.

El diagrama de barras de error en la figura 2, indican que no es distinto la percepción de la gestión curricular universitaria entre los estudiantes del género femenino y masculino, aunque las estudiantes, indican que la gestión no responde a los propósitos educativos de su formación profesional, es decir, la composición, cohesión, coherencia y proyección curricular es poco adecuado o "los procedimientos establecidos en la gestión curricular en alguna medida se ajustan a los propósitos de formación profesional de los estudiantes". Esto se corrobora por los resultados del estadígrafo U de Mann-Whitney.

\section{Tabla 7}

Estadísticos de la prueba U de Mann-Whitney de la gestión curricular universitaria por género

\begin{tabular}{lc}
\hline & Gestión curricular universitaria \\
\hline U de Mann-Whitney & 6955,000 \\
$\mathrm{Z}$ & $-0,821$ \\
Significancia asintótica (Valor P) & 0,412 \\
\hline
\end{tabular}

a. Variable de agrupación: Género 
La significancia asintótica o valor P es 0,412 (41,2\%) cuyo valor es mayor al nivel de significancia del 5\%, demostrando que el género de los estudiantes universitarios no afecta en la percepción de la gestión curricular universitaria, donde ambos géneros perciben la misma problemática.

\section{Figura 3}

Barras de error de la gestión curricular por área de conocimiento

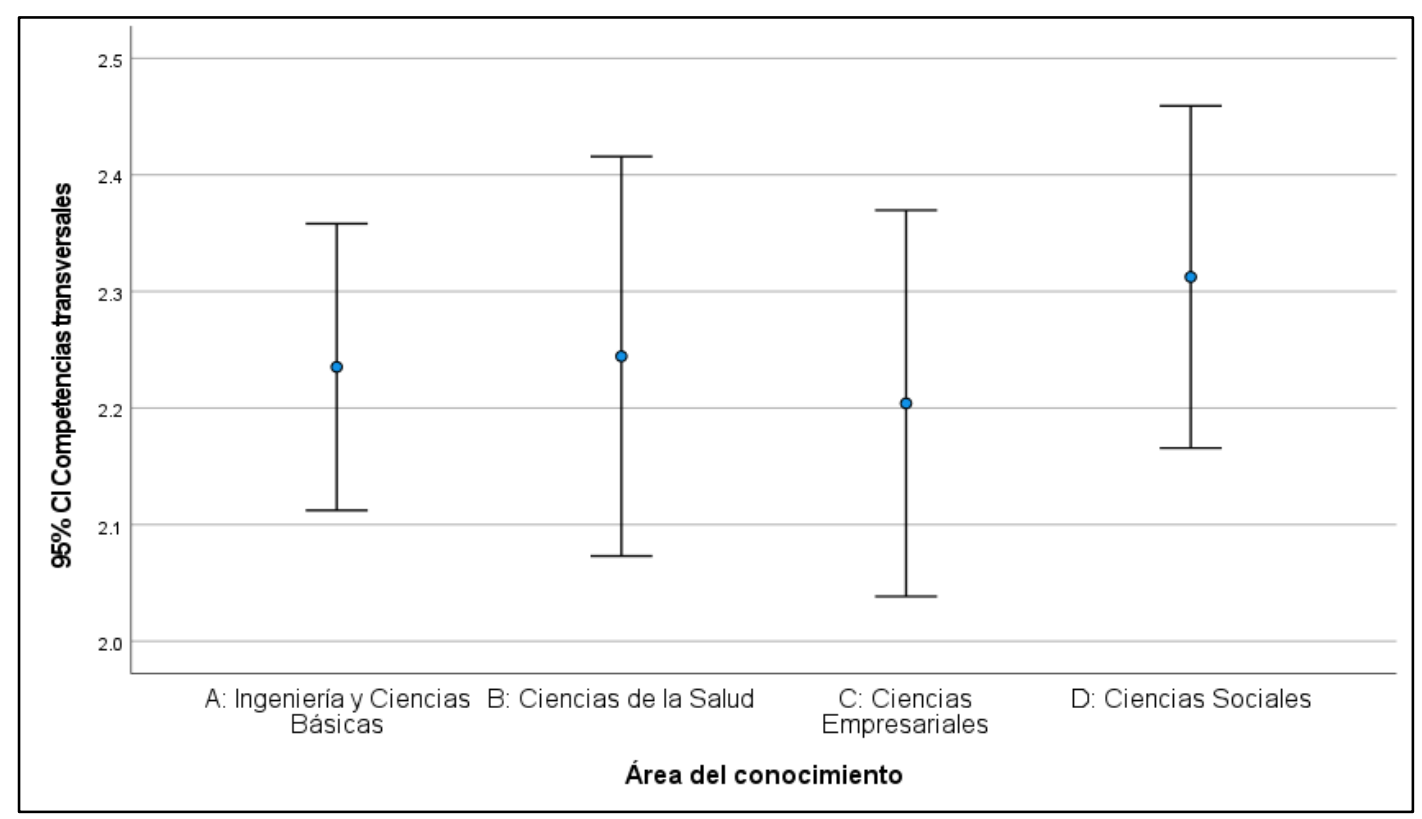

Nota: Resultados del programa estadístico IBM SPSS.

El diagrama de barras de error de la figura 3, evidencia que no existen diferencias en cuanto a la percepción de la gestión curricular según el área de conocimiento, donde la distribución de las escuelas profesionales por área de conocimiento, coindicen en percibir un nivel "poco adecuado" de la organización del plan de estudios, la semestralización presenta requisitos de asignaturas poco coherentes para que los estudiantes puedan concluir en el tiempo programado, esta situación ocurre cuando se presentan los catálogos de asignaturas en cada semestre académico, generando malestar en los estudiantes que aprueban las asignaturas en las que se matricularon, y con mayor razón el problema de los requisitos se evidencian en grupos de estudiantes con promedios ponderados, limitándoles en el avance, obligándolos a terminar en un semestre más de lo previstos o incluso más semestres. La figura demuestra la existencia de estos hechos en casi todas las escuelas profesionales de la universidad. Para confirmar esta ocurrencia se analizó con el estadígrafo H de Kruskal-Wallis. 


\section{Tabla 8}

Estadísticos de la prueba $H$ de Kruskal-Wallis de la gestión curricular universitaria por área de conocimiento

\section{Gestión curricular universitaria}

\begin{tabular}{lc}
\hline H de Kruskal-Wallis & 2,363 \\
Grados de libertad & 3 \\
Significancia asintótica (valor P) & 0,501
\end{tabular}

a. Prueba de Kruskal Wallis

b. Variable de agrupación: Área del conocimiento

Los resultados del estadígrafo $\mathrm{H}$ de Kruskal-Wallis, presenta un valor de 2,363 con un valor P de 0,501 (50,1\%), este valor es mayor al nivel de significancia del 5\% $(0,05)$, demostrando que el área de conocimiento (A. Ingeniería y Ciencias Básicas, B. Ciencias de la Salud, C. Ciencias Empresariales y D. Ciencias Sociales) no difiere en la percepción que se tiene respecto a la gestión curricular, donde casi todas las escuelas profesionales demuestran problemas similares en referencia a la composición, cohesión, coherencia y proyección curricular.

\section{Tabla 9}

Estadísticos descriptivos de las competencias transversales

\begin{tabular}{|c|c|c|}
\hline Categorías & Frecuencia & Porcentaje \\
\hline Insatisfactorio & 17 & $7,0 \%$ \\
\hline Mejorable & 148 & $60,9 \%$ \\
\hline Satisfactorio & 78 & $32,1 \%$ \\
\hline Total & 243 & $100,0 \%$ \\
\hline
\end{tabular}

Los resultados evidencian un desarrollo mejorable de las competencias transversales en un 60,9\%; entendiéndose que las competencias instrumentales, personales y sistemáticas no demuestras un efectivo logro satisfactorio, pues solamente el $32,1 \%$ si están logrando. Es necesario mencionar que las competencias transversales o genéricas posibilitan al egresado o futuro profesional un mejor desempeño en los escenarios laborales donde se desenvuelvan. Es probable el poco desarrollo de las capacidades de trabajo en equipo, toma de decisiones, trabajo autónomo, control emocional, organización y planificación. 


\section{Tabla 10}

Rangos promedio de las competencias transversales por el género de los estudiantes

\begin{tabular}{llccc}
\hline & Género & N & $\begin{array}{c}\text { Rango } \\
\text { promedio }\end{array}$ & $\begin{array}{c}\text { Suma de } \\
\text { rangos }\end{array}$ \\
\hline Competencias & Femenino & 130 & 115,98 & 15077,00 \\
transversales & Masculino & 113 & 128,93 & 14569,00 \\
& Total & 243 & & \\
\hline
\end{tabular}

Los rangos promedio de los géneros masculino y femenino es similar, esto muestra de acuerdo con lo mencionado en la tabla 9, el poco desarrollo que vienen evidenciando en las competencias instrumentales, personales y sistemáticas aún no alcanzan un nivel satisfactorio, y es muy probable como se ha mencionado tengan mayor dificultad en aquellas habilidades donde se requiere un mayor esfuerzo por parte del estudiante universitario.

\section{Figura 4}

Barras de error de las competencias transversales por género

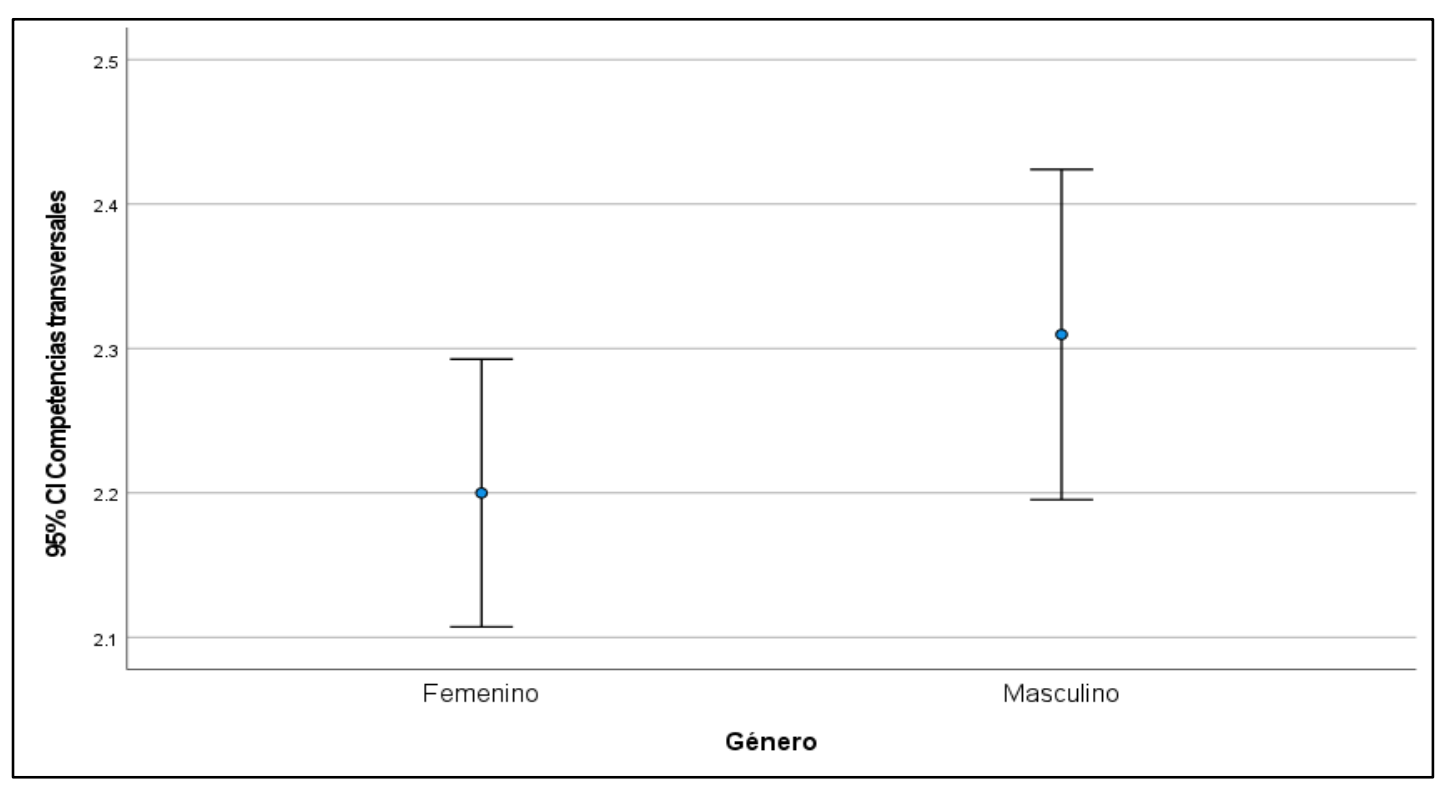

Nota: Resultados del programa estadístico IBM SPSS.

El diagrama de barras de error en la figura 4, indican un desarrollo similar en el desarrollo de las competencias instrumentales, personales y sistémicas en los estudiantes del género masculino y femenino, pero también observamos que el grupo de los estudiantes masculinos muestran un mayor desarrollo en la toma de decisiones, trabajo en equipo, creatividad e innovación, adaptabilidad y actitud emprendedora.

Esto se corrobora por los resultados del estadígrafo U de Mann-Whitney. 


\section{Tabla 11}

Estadísticos de la prueba $U$ de Mann-Whitney de las competencias transversales por género

\begin{tabular}{lc}
\hline & Competencias transversales \\
\hline U de Mann-Whitney & 6562,000 \\
$\mathrm{Z}$ & $-1,665$ \\
Significancia asintótica (Valor P) & 0,096 \\
\hline
\end{tabular}

a. Variable de agrupación: Género

La significancia asintótica o valor P es 0,096 (9,6\%) cuyo valor es mayor al nivel de significancia del 5\%, demostrando que el género de los estudiantes universitarios no afecta en la percepción del desarrollo de las competencias transversales, donde ambos géneros demuestran un similar nivel de logro las competencias instrumentales, personales y sistémicas, entonces si hay logro de capacidades o habilidades estas presentan similitudes así como también las dificultades se evidencian similarmente, probablemente lo aciertos más notorios es el empleo de las tecnologías de la información y comunicación, creatividad e innovación, investigación y actitud emprendedora.

\section{Figura 5}

Barras de error de las competencias transversales por área de conocimiento

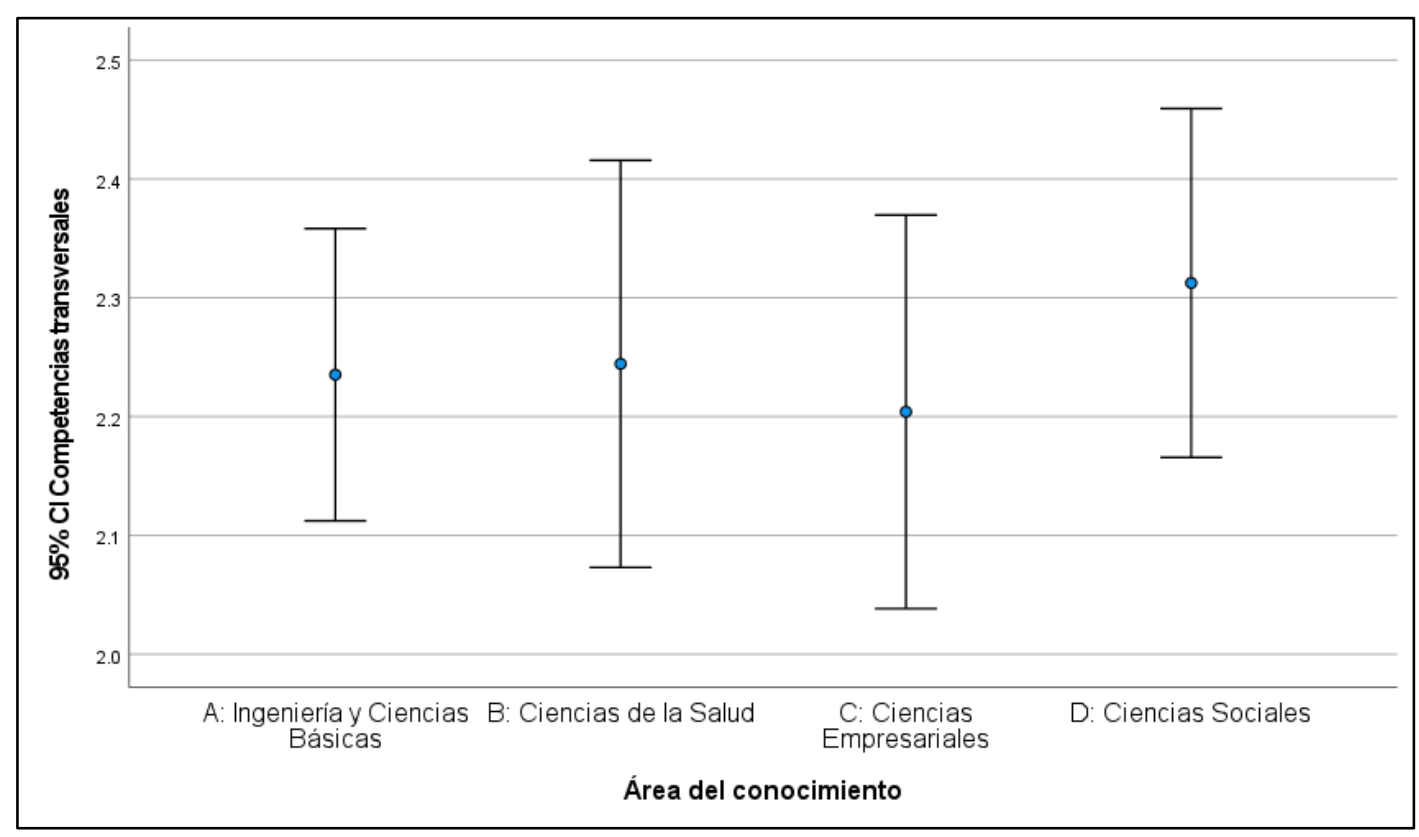

Nota: Resultados del programa estadístico IBM SPSS.

El diagrama de barras de error de la figura 5, evidencia que no existen diferencias en cuanto al grado de desarrollo de las competencias profesionales de acuerdo al área de 
conocimiento, entonces en casi todas las escuelas profesionales de la universidad es notorio la ocurrencia de un nivel mejorable, donde las capacidades que requieren mayor atención son aquellas donde demandan mayor esfuerzo del estudiante universitario, como no existen diferencias en las áreas y tampoco en el género, demostrándose la ocurrencia del mismo grado de dificultad al momento de organizar y planificar sus actividades, universitarias, al momento de tomar decisiones, en el control adecuado de sus emociones, en el trabajo autónomo y en el trabajo en equipo, debido a la cultura de aprendizaje adquirido durante la etapa escolar. Para confirmar esta ocurrencia se analizó con el estadígrafo H de Kruskal-Wallis.

\section{Tabla 12}

Estadísticos de la prueba $H$ de Kruskal-Wallis de las competencias transversales por área de conocimiento

\begin{tabular}{lc}
\hline & Competencias transversales \\
\hline H de Kruskal-Wallis & 1,198 \\
Grados de libertad & 3 \\
Significancia asintótica (valor P) & 0,753 \\
\hline
\end{tabular}

a. Prueba de Kruskal Wallis

b. Variable de agrupación: Área del conocimiento

Los resultados del estadígrafo $\mathrm{H}$ de Kruskal-Wallis, presenta un valor de 1,198 con un valor P de 0,753 (75,3\%), este valor es mayor al nivel de significancia del 5\% $(0,05)$, demostrando que el área de conocimiento (A. Ingeniería y Ciencias Básicas, B. Ciencias un universitarios presentan similar grado de desarrollo de las competencias profesionales, donde casi todas las escuelas profesionales demuestran similitud en cuanto al grado de desarrollo de las competencias instrumentales, personales y sistémicas.

\section{Tabla 13}

Rangos promedio de las competencias transversales según la gestión curricular universitaria

\begin{tabular}{lccc}
\hline & $\begin{array}{c}\text { Gestión curricular } \\
\text { universitaria }\end{array}$ & $\mathbf{N}$ & $\begin{array}{c}\text { Rango } \\
\text { promedio }\end{array}$ \\
\hline \multirow{2}{*}{ Competencias } & Inadecuado & 4 & 9,00 \\
transversales & Poco adecuado & 131 & 91,94 \\
& Adecuado & 108 & 162,65 \\
& Total & 243 & \\
\hline
\end{tabular}


Los rangos promedios del grado de gestión curricular universitaria provocan en las competencias transversales, un desarrollo diferenciado en cada uno de sus niveles, de acuerdo con el grado de gestión curricular, se alcanza un grado insatisfactorio, mejorable y satisfactorio de las competencias instrumentales, personales y sistémicas. Los rangos en cada caso difieren notoriamente, otorgando a la gestión curricular como un factor fundamental para alcanzar un satisfactorio u optimo logro de las competencias transversales, provocando en los futuros egresados un mejor desenvolvimiento y desempeño laboral.

\section{Figura 6}

Barras de error de las competencias transversales según la gestión curricular universitaria

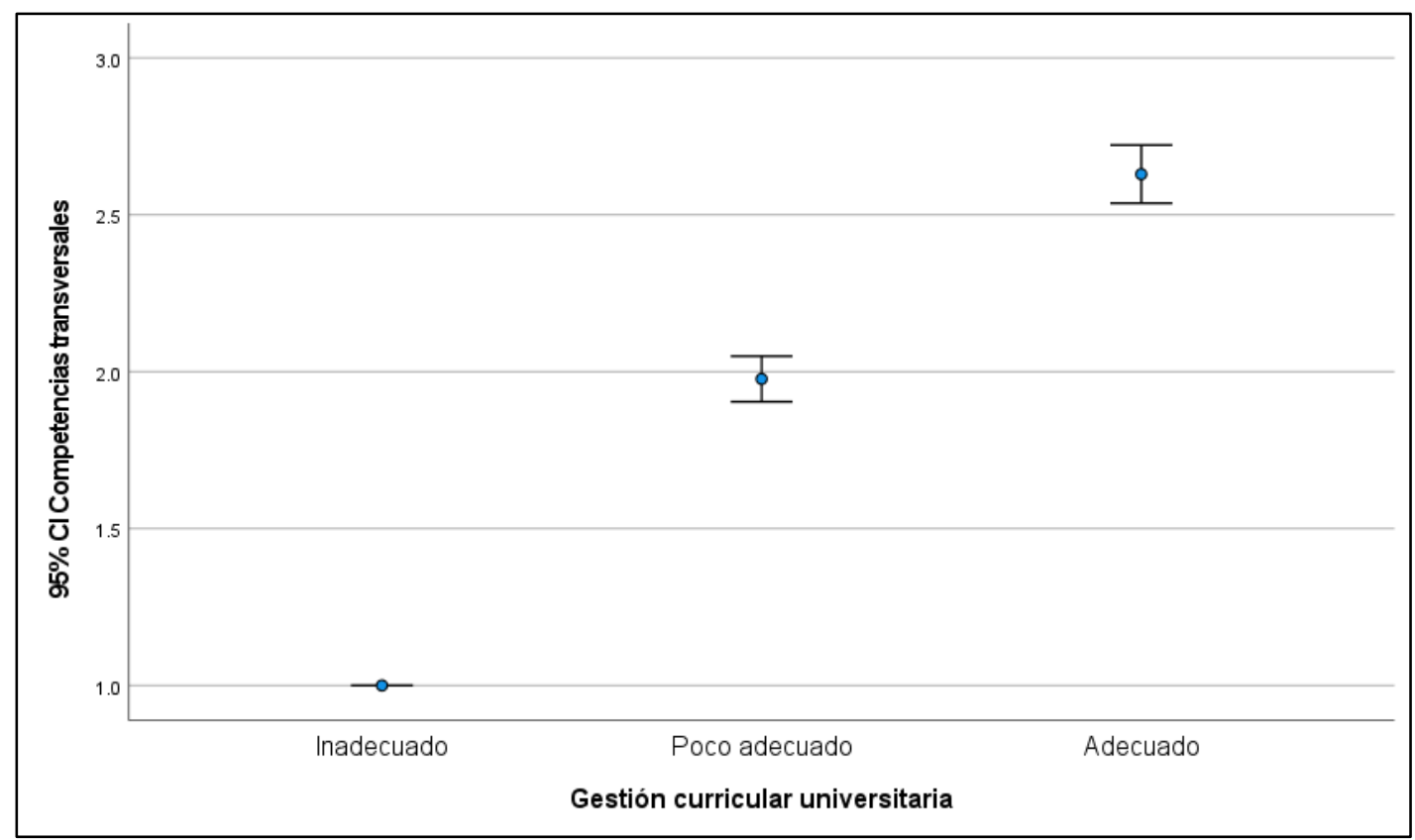

Nota: Resultados del programa estadístico IBM SPSS.

Los diagramas de barras de error muestran diferencias en su comportamiento, debido a la influencia o correspondencia evidente, debido a grado de participación de la gestión curricular universitaria, mientras esta se adecue a los procedimientos establecidos, esta condición responderá pertinentemente a los propósitos de la formación profesional de los estudiantes, propiciando un óptimo aprendizaje. 


\section{Tabla 14}

Estadísticos de la prueba $H$ de Kruskal-Wallis de las competencias transversales según la gestión curricular universitaria

\begin{tabular}{lc}
\hline & Competencias transversales \\
\hline H de Kruskal-Wallis & 95,064 \\
Grados de libertad & 2 \\
Significancia asintótica (valor P) & $<0,001$ \\
\hline
\end{tabular}

a. Prueba de Kruskal Wallis

b. Variable de agrupación: Gestión curricular universitaria

La prueba estadística de H de Kruskal-Wallis o ANOVA de Kruskal-Wallis, demuestra diferencias en los diferentes niveles de las competencias transversales, debido a que el valor $\mathrm{P}$ es menor al nivel de significancia del $5 \%(0,05)$. Cuando la gestión curricular muestra un nivel inadecuado propicia el logro insatisfactorio de las competencias transversales (rango promedio=9,00), en el caso de una gestión curricular universitaria poco adecuada, se tiene un logro mejorable de las competencias transversales (rango promedio=91,94) y si la gestión curricular universitaria es adecuada, es posible alcanzar un logro satisfactorio de las competencias transversales (rango promedio=162,65), demostrándose la importancia adecuada de la gestión curricular universitaria, donde los procedimientos establecidos deben responder a los propósitos de formación profesional de los estudiantes enfocado en el óptimo aprendizaje, propician el desarrollo o logro satisfactorio de las competencias transversales de los estudiantes, desarrollado convenientemente su capacidad cognitiva, autónoma y reflexiva crítica, producto del pensamiento crítico, dado por la actitud reflexiva, activa y autónoma desplegada en su cotidianidad.

\subsection{Discusión}

Se llevó a cabo adicionalmente el análisis de la desviación estándar (sin el uso de los baremos), resultado de la sumatoria de las respuestas de los participantes del estudio, esto con el fin de observar comportamiento de los datos con el fin de contribuir en la interpretación de los resultados.

La desviación estándar en el caso de la gestión curricular universitaria es $\mathrm{DE}=10,437$, a diferencia de las competencias transversales que tiene una $\mathrm{DE}=12,977$, se observa una diferencia notoria en ambas medidas de dispersión. Estos estadísticos demuestran que las competencias transversales en muchas escuelas profesionales no se están desarrollando 
de la misma manera, o así lo perciben los estudiantes, entonces no existe un acercamiento idéntico tampoco en las áreas de conocimiento, mientras la gestión curricular por ser un aspecto que la universidad gestiona a través del Vicerrectorado Académico, la mayoría de escuelas profesionales coincide en la forma de implementar los procedimientos de la gestión curricular con la finalidad de alcanzar los propósitos de la formación profesional de los estudiantes, lo mismo ocurre en las áreas del conocimiento que agrupa la Universidad Nacional de San Antonio Abad del Cusco.

Con el fin de fundamentar la importancia de la gestión curricular en el desarrollo de las competencias transversales, se aplicó el estadígrafo correlación de Spearman, resultado el valor del coeficiente de correlación $\mathrm{Rho}=0,748$ y con valor $\mathrm{P}=0,001$ siendo menor al nivel de significancia del $5 \%$. Esto demuestra la necesidad de un desarrollo curricular enfocado en la necesidad de mejorar la efectividad del proceso de su gestión. Al respecto Crespo et al. (2021) menciona la importancia de contar con líderes que contribuyan en el proceso de revisión de los currículos de estudio, esto permitirá que se tomen decisiones pertinentes y otorgar un seguimiento pertinente a las fases del proceso curricular, asimismo es necesario contar con la mayor cantidad de docentes en el equipo de revisión y diseño curricular, con el fin de promover una cultura colaborativa, para lo cual es propicio motivar a los docentes y empoderarlos en temas referentes al rediseño curricular, fomentando la reflexión de la función del proceso educativo universitario y promover propuestas innovadoras.

$\mathrm{Al}$ respecto es considerable el aporte realizado por Crespo et al., partiendo de la selección de líderes comprometidos con la gestión curricular, sobre todo al momento de realizar las actividades de rediseño curricular, y entre otros aspectos antes mencionados. En el caso de la Universidad Nacional de San Antonio Abad del Cusco, esta situación se practica, pero no se tiene en cuenta los detalles apropiados de selección de lideres, también se realizan talleres de sensibilización y necesidad del trabajo en equipo, pero aun así no se tiene un compromiso, al principio varios docentes participan, pero conforme pasa el tiempo, van alejándose del objetivo. Para evitar esta situación es necesario proponer políticas que favorezcan la comunicación, el compromiso e incentivos que favorezcan a mantenerlos motivados, todo esto paulatinamente debe ser implementado, para así evitar un rechazo masivo de los docentes. 
En el caso de las competencias profesionales como se evidencia en los resultados, la universidad en todas sus escuelas profesionales similarmente mantiene el mismo logro de competencias trasversales, de acuerdo con lo señalado por Rey (2001), una utilidad importante es fomentar la conformación y despliegue de equipos de trabajo pluridisciplinarios, complementando lo mencionado por Villardón (2016), las competencias claves o transversales están orientadas a perfeccionar los conocimientos técnicos especializados, con el fin de prepararlos para un mercado laboral cada vez competitivo y exigente.

En ese entender, no solamente los estudiantes de la Universidad Nacional de San Antonio Abad del Cusco deben comprender la necesidad de alcanzar un óptimo desarrollo de las competencias transversales, sino debe comprenderse desde los líderes o quienes están encargados de administrar y gestionar el currículo de estudios de las diferentes escuelas profesionales, asimismo es necesario la participación de todos los docentes y también deben entender su valor en el proceso formativo de los estudiantes, para de esta formar lograr un mejor desempeño profesional, respondiendo a los requerimientos de sus empleadores.

\section{CONCLUSIONES}

Después de la ejecución de los procedimientos del estudio, se logró evaluar la articulación de la gestión curricular universitaria con el desarrollo de las competencias transversales en estudiantes de pregrado, demostrándose a través del estadígrafo H de Kruskal-Wallis, con un valor P significativo, la necesidad de una adecuada composición, cohesión, coherencia y proyección de la gestión curricular con la finalidad de lograr en el estudiante el desarrollo de las competencias instrumentales, personales y sistémicas, evidenciando algunas deficiencias, pues solamente se evidencia en el 44,4\% de los datos una adecuada gestión curricular universitaria, en el caso de las competencias transversales en el 32,1\% se puede observar un logro satisfactorio, esto denota, la necesidad de ponderar, impulsar y consolidar la articulación entre la gestión curricular y las competencias transversales, de manera que la gestión curricular se ajuste a las necesidades formativas de los estudiantes, involucrando y propiciando el logro de habilidades que resultan para el estudiante más exigentes, como es el caso del trabajo equipo, la organización y planificación de las actividades universitarias y personales, toma de decisiones, control emocional, investigación y la creatividad e innovación. 
La gestión curricular universitaria no muestra diferencias en cuanto a su composición, cohesión, coherencia y proyección curricular, porque los resultados demuestran que la mayoría de escuelas profesionales cuentan con un nivel poco adecuado del 53,9\%, manifestando la existencia de problemas al momento de gestionar el currículo de estudios, donde solamente se le presta atención cuando llegan periodos de cambios debido a las exigencias de las entidades del Estado, específicamente dado por la Superintendencia Nacional de Educación Superior Universitaria (SUNEDU), cuando debería tener periodos de revisión y si está debidamente articulado con la formación por competencias, done es necesario la implementación de políticas y procedimientos de revisión, innovación y adaptación a las exigencias de un mercado laboral cada vez más exigente.

Las competencias transversales, tampoco muestran diferencias significativas en cuanto su desarrollo en las distintas escuelas profesionales, entendiéndose que el nivel mejorable del 60,9\% caracteriza a la mayoría de estudiantes con dificultades para logar desarrollar las competencias instrumentales (aun requieren de apoyo para afianzar en la organización y planificación, gestión de la información y comunicación, toma de decisiones y diseño de proyectos profesionales y personales), competencias personales (aun presentan dificultades para realizar trabajos en equipo, no hay un buen control emocional) y en las competencias sistémicas (aun no son capaces de propiciar satisfactoriamente la creatividad e innovación, el trabajo autónomo y la investigación).

\section{LISTA DE REFERENCIAS}

Álamo, G. (2015). Metodología para el diseño curricular en los Programas Nacionales de Formación (PNF). Espacio Abierto, 24(4), 129-150.

Alsina, J., Boix, R., Burset, S., Buscà, F., Colomina, R. M., García, M. Á., Mauri, T., Pujolà, J. T., \& Sayós, R. (2011). Evaluación por competencias en la universidad: Las competencias transversales (Primera edición). Ediciones OCTAEDRO.

http://diposit.ub.edu/dspace/bitstream/2445/145000/1/18cuaderno.pdf

Andrews, J., \& Higson, H. (2008). Graduate employability, "soft skills" versus "hard" business knowledge: A european study. Higher Education in Europe, 33(4), 411-422. https://doi.org/10.1080/03797720802522627

Benavidez, M. F., \& Vásquez, L. (2019). La importancia de la gestión curricular universitaria en programas a distancia, estudio Institución de Educación 
Superior Suramericana. In Crescendo, 10(1), 13-34. https://doi.org/https://doi.org/10.21895/incres.2019.v10n1.02

Concepción, M. R., \& Rodríguez, F. de la T. (2016). Gestión curricular universitaria en la adaptación al enfoque de competencias. Opción, 32(11), 315-335.

Crespo, A., Mortis, S. V., \& Herrera, S. R. (2021). Gestión curricular holística en el modelo por competencias: un estudio exploratorio. Formación Universitaria, 14(4), 3-14. https://doi.org/10.4067/S0718-50062021000400003

Duque, E. J. (2009). La gestión de la universidad como elemento básico del sistema universitario: una reflexión desde la perspectiva de los stakeholders. Revista Innovar. Edición Especial En Educación, 25-42. http://www.scielo.org.co/pdf/inno/v19s1/19s1a03.pdf

Elorza, H. (2008). Estadística para las ciencias sociales del comportamiento y de la salud (3a edición). Cengage Learning Editores, S.A.

Eurostat [Statistics Explained]. (2016). Employment - annual statistics. https://ec.europa.eu/eurostat/statisticsexplained/index.php?title=Employment_-_annual_statistics

González, N., \& Martínez, P. (2020). Relevancia de las competencias transversales en el desarrollo profesional del graduado. Percepción del estudiante. Profesorado, 24(2), 388-413. https://doi.org/10.30827/PROFESORADO.V24I2.15041

Hernández, L. (2017). Rediseño curricular de la carrera gestión social y desarrollo de la Universidad de Otavalo para su proceso de acreditación. Formacion Universitaria, 10(6), 3-16. https://doi.org/10.4067/S071850062017000600002

Hernández Sampieri, R., \& Mendoza Torres, C. P. (2018). Metodología de la investigación: Las rutas cuantitativa, cualitativa y mixta (Primera edición). McGRAW-HILL Interamericana Editores, S.A. de C. V.

Ministerio de Educación del Perú. (2017). Currículo Nacional de la Educación Básica. http://www.minedu.gob.pe/curriculo/pdf/curriculo-nacional-de-laeducacion-basica.pdf

Osorio Villegas, M. (2017). El currículo: Perspectivas para acercarnos a su comprensión. Zona Próxima, 26, 140-151. https://doi.org/10.14482/zp.26.10205 
Pardasani, M. (2018). Recruiting, engaging, and educating social work leaders: an innovative curricular model. Social Work Education, 37(4), 519-534. https://doi.org/10.1080/02615479.2018.1439002

Pérez, J. E., García, J., \& Sierra, A. (2013). Desarrollo y evaluación de competencias genéricas en los títulos de grado. Revista de Docencia Universitaria, 11(Número especial), 175-196.

Prising, J. (2017). La Revolución de las Competencias: Talento, empleabilidad y tecnología. ManpowerGroup. https://www.manpowergroup.es/infome-larevolucion-de-las-competencias-talento-empleabilidad-tecnolog\%C3\%ADa

Rey, B. (2001). Las competencias transversales en cuestión. www.philosophia.cl

Rodríguez, S., Prades, A., Bernáldez, L., \& Sánchez, S. (2010). Sobre la empleabilidad de los graduados universitarios en Catalunya: del diagnóstico a la acción. Fecha de Entrada, 351, 15-22. www.aneca.es/estudios/docs/InformeejecutivoANECA_jornadasREFLEXV 20.pdf

Sánchez, Á., López, M. Á., \& Fernández, M. V. (2010). Análisis de las competencias genéricas en los nuevos títulos de grado del EEES en las universidades españolas. Revista de Docencia Universitaria, 8(1), 35-73. https://dialnet.unirioja.es/servlet/articulo?codigo $=4014853$

Swain, R., \& Grasa, P. L. (2010). Modelo Educativo del Tecnológico de Monterrey (MET) PDF Free Download. Portal Web Docplayer. https://docplayer.es/32466330-Modelo-educativo-del-tecnologico-demonterrey-met.html

Unión Europea. (2015). Guía de uso del ECTS. https://ec.europa.eu/education/sites/default/files/document-librarydocs/ects-users-guide_es.pdf

Villalaz, E. S., \& Medina, P. (2020). El currículo universitario peruano: aspectos complejos. Maestro $\quad y \quad$ Sociedad, 121-136. https://maestroysociedad.uo.edu.cu/index.php/MyS/article/view/5184

Villardón, L. (2016). El porqué y el cómo de las competencias genéricas en educación superior. In C. Díaz (Ed.), Las competencias genéricas en la educación 
Gestión curricular en el desarrollo...

superior (Primera edición, pp. 15-44). Editorial de la Dirección de Asuntos Académicos de la PUCP.

Yániz, C., \& Villardón, L. (2006). Planificar desde competencias para promover el aprendizaje. Publicaciones de la Universidad de Deusto. 